\title{
Entrepreneur Transformational Leadership for SME's Business Sustainability
}

\author{
A. Sulaeman *, E.T. Sule, H. Hilmiana, M.F. Cahyandito \\ Universitas Padjadjaran \\ Bandung, Indonesia
}

\begin{abstract}
The soybean-based industry in West Java had proven as business that can survive in the long term with highly increasing demand. But, at present the number of business unit is declining and entrepreneurs are constrained by internal and external factors that will ultimately threaten their business sustainability. To solve these problems, the role of entrepreneurs as the main control holder with transformational leadership is highly needed. This study aims to determine the effect of transformational leadership on business sustainability. Using a theory of, this research was conducted with survey of CFA to confirm a questionnaire in-strument to 100 entrepreneurs of SMEs based on West Java soybean. The data obtained were processed by Structural Equation Modeling analysis. The result of research reveals that there is a significant influence of transformational leadership toward business sustainability. Government regulation and stakeholder were mod-erating variables of transformational leadership influence on business sustainability of SMEs. It is expected, that this research will contribute to the development of SME leadership, regulatory support and stakeholders.
\end{abstract}

Keywords-Entrepreneur Tranformational Leadership; SMEs; Business Sustainability

\section{INTRODUCTION}

Small and Medium Enterprises (SMEs) have a strategic role to the Indonesian economy, especially in terms of employment, contribution to GDP and non-oil exports. SMEs are often faced with business sustainability problems achieved by balancing economic, social and environmental. Business sustainability is important for SMEs because lack of government's coordination, so it is vulnerable to violations of product safety and environmental pollution in business activities. Many kinds of food made from soy-bean are special Indonesian food that have been known for a long time in the community. The food can be produced at the household level so that soy based food is part of the nation's culture. SME's soybean based, include tempeh, tofu, milk, and flour which are mostly informal sectors in the industry which experienced the highest demand among other businesses i.e., from 38\% in 1998 to $63 \%$ in 2002 The National Socioeconomic Survey (SUSENAS) in1998-2002. West Java is Indonesia's the fourth largest producer of soybeans that supplies $23 \%$ of national soybean demand. However, SMEs soy bean-based products centres in West Java decreased since 2010 until now. The problem of decreasing the number of business units in West Java shows the inability of entrepreneurs in maintaining business sustainability even though local soybean production is relatively high. This is what underlies West Java to serve as the location of research on business sustainability.

\section{LITERATURE REVIEW}

SMEs that have a small scale, large number have an important and strong impact from their business activities for the country's economy, socioeconomic conditions and environmental sustainability. This is in accordance with Azzone, [1] research that SMEs are often faced with various obstacles in addition to the main obstacles that often occur such as low levels of profitability.

The Human Resource Management Approach (HRM) is the most important approach because business sustainability is an area of HRM that encompasses multidimensional and multidisciplinary human and organizational behaviour. The importance of the sustainability concept in HRM is motivated by the lack of labor skills and efforts to overcome the negative impact of human resource policies on employees [2] suggested the reason for sustainability is important for HRM, because (1) HRM helps direct employee mindset and action toward achieving sustainability goals (HRM is treated as means). (2) Sustainability principles can be embodied in HRM systems that cause the long term physical, social, and economic wellbeing of employees. Thus this study aims to determine the effect of transformational leadership and stakeholder engagement to business sustainability.

\section{MethodOLOGY}

This research was conducted using a survey through crosssectional one shoot. The unit of analysis in this study was the owners of Small and Medium Enterprises (SMEs), which were engaged in soy-bean-based industries, such as tempeh, tofu, soy sauce, and other soy products such as tauco, milk and flour. Observation used the cross-section. This study used intervening variables, so the approach in modeling and technique solutions used as an analytical tool is a method of structural equation modeling (SEM). The reason for choosing this method is the ability to measure constructs directly and indirectly, through the indicators and analyze the indicator variables, latent variables, following the measurement errors. This study used a combination of data collection consisting of interviews, questionnaires and observations. The questionnaire was first tested to examine the level of validity and reliability.

\section{RESULT AND DISCUSSION}

The results of this study included descriptive results that test the relationship between variables. There are three variables used in this research including business sustainability, transformational leadership, and stakeholder 
engagement. In transformational leadership variables, entrepreneurs are relatively good in the ability to influence and relatively low in social responsibilities. Relative stakeholder variables are relative in building trust, but low in the company's ability to understand needs.

Business sustainability refers to the integration of economic, environmental, and social considerations on the part of corporations [3], [4]. In this study, business sustainability is shown by three sub of variables, such as the economic, social and environment. The economic was indicated by total of sales, net income and ability to meet market needs. The social sub of variables was indicated by of fair wages, work safe-ty and occupational health. Environmental sub of variables was indicated by decreasing waste from the relevant factories, decreasing energy use, decreasing $\mathrm{CO} 2$ emissions, and the ability to recycle. Transformational leadership consists of three sub of variables, such as agent of change, visionary, and in-fluence. The descriptive results of this study are shown in.

Table 1. Descriptive results of analysis.

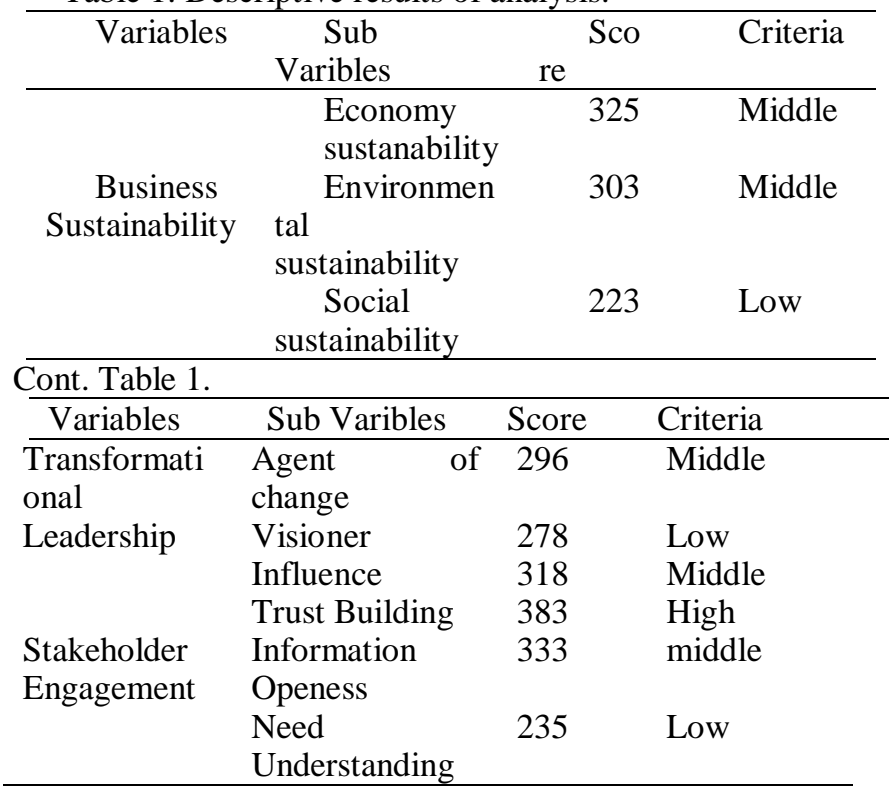

Descriptive result on business sustainability reveals that economic sustainability is better than social sustainability. It means that leaders' ability to achieve revenue and profit is better than their ability to participate in the social activities.

Transformational leadership means leaders' ability to transform the personal values of followers to support the vision and goals of the organization by fostering an environment where relationship can be formed and by establishing a climate of trust in which vision can be shared. In this case, leaders are able to provide passion, energy, inspiration to their employees. Leaders also provide knowledge as a source of knowledge and good experience for. Through these leaders, employees can improve skills, talents and ability to work to generate profits, act environmentally friendly and more ethical to the surrounding community. The transformational leader shows a sympathetic attitude towards his followers and re-mains a loving leader for providing direction and interaction. Transformational leadership is demonstrated by the leader's ability to make changes to more efficient production methods and reduce waste, affect employees to strive to achieve order or sales targets, gain profitable inputs, and environmentally-friendly production activities. The result of this research shows that transformational leadership was showed by leader's ability to influence their employees but low in anticipating and predicting for the future. Leaders harness their power, experience and knowledge through friendly discussions and interactions, supportive of suggestions and acknowledgments, and ultimately, through transparent and profitable integration behaviours. Attitude, social, and fun to followers, in addition to possessing all relevant coercive powers and authorities facilitate and encourage them to instill their needs and ideas to leaders and to develop their skills, knowledge, and expertise openly. The attitude of transformational leaders who are interactive and supportive helps them to engage their followers in achieving their goals and motivating subordinates.

Stakeholder Engagement consists of three sub of variables such as, building trust, information disclosure and understanding needs. Building trust is demonstrated by the ability to display good performance and keep promises. Information disclosure is indicated by the intensity of informing shareholders of total sales, profits and business constraints. Understanding of needs is indicated by knowledge of the needs of wage levels, work time, workload, health, safety, earnings information needs, business stability needs and understanding of the accuracy of payment obligations. According to [5] the understanding of SMEs on the different interests of each stakeholder will create business sustainability through six stages, such as (i) identification of needs (ii) linking stakeholders (iii) prioritizing stakeholders (vi) taking targets into action. This research reveals that leader's ability to build stakeholder's trust is higher than open information and understand stakeholder needs. It means that leaders can show good performance and keep promise tightly.

From the results of the data analysis, both direct and indirect effect of transformational leadership to business sustainability is yielded. In this case, $32.4 \%$ of business sustainability is affected by transformational leadership, and $52.4 \%$ of business sustainability is affected by transformational leadership with mediating roles of stakeholder engagement such as shareholders, suppliers, customers and employees.

External factors affecting business sustainability are stakeholder factors. According to [6], external factors consist of the government, customers and stakeholders (suppliers). Whereas according to stakeholder theory [7], stakeholders consist of customers, owners, employees, suppliers, government, and society. These stakeholders join and collaborate and work together to build business sustainability. The indirect influence of transformational leadership on business sustainability through engagement stakeholders is greater than the direct influence. This shows that 
transformational leaders can establish a good relationship with internal stakeholders, such as employees and shareholders and external stakeholders, namely customers and suppliers. In addition, research supporting the relationship between stakeholder engagement and business sustainability is carried out by [8] stating that stakeholder engagement is mentioned as a mechanism to drive sustainability. (Rhodes et al. 2014) states that stakeholder engagement is a key variable between network stakeholders (internal and external factors) and results. Other key factors are human capital/talent, technology, culture, and processes such as collaboration, knowledge sharing, and co-creation of value with stakeholders. The constraints of SMEs in practicing the balance of economic, social and environmental management are (1) lack of resources, especially financial (2) unclear organizational structure (3) lack of environmental oriented HR training (4) limited access to technology (5) low level of innovation. The implementation of the concept of achieving business sustainability is not an additional burden for SMEs, it is hoped that through this concept, SMEs will become more efficient in their operations with leaders (entrepreneurs). SMEs are visionary leaders and continue to progress towards better ones.

Based on the results of descriptive and data processing research, the results show that the ability of leaders to influence employees is able to increase stakeholder confidence with the ability to show good performance, ability to fulfill obligations, fulfill orders and provide good services to stakeholders. Likewise, stakeholder trust will increase economic sustainability. Increased economic sustainability as a result of high stakeholder confidence occurs because the trust made is able to increase the additional capital from shareholders and increase the stability of raw material supply.

From the results of the study it was also revealed that the leader's visionary abilities were demonstrated by knowing market opportunities, knowledge of effective production methods, and knowledge of predicting low markets. This causes the ability to understand low employee needs, including the ability to understand wage and compensation needs, proper welfare and occupational health and safety needs. The low understanding of employee needs causes low social sustainability which includes wage inequality, low quality of occupational health and low quality of work safety.

\section{CONCLUSION}

This study reveals that business sustainability in SMEs in West Java is relatively good in economic sustainability performance but low in social and environmental performance. Besides that, transformational leadership, it is relatively good in the ability to influence employees to be able to improve their performance and relatively low in anticipating future challenges. In the case of stakeholder engagement, entrepreneurs strive to build good trust with stake-holders, especially shareholders and suppliers in fulfilling their obligations and providing business shareholders with benefits and business stability. But entrepreneurs are relatively low in terms of the ability to meet employee needs, especially bonuses, family allowances and holidays. In this study, there was a positive relationship between transformational leadership and business sustainability both directly and indirectly. Indirect influence through engagement stakeholders is stronger than the direct influence indicating that business sustainability needs the support of strong stakeholder participation, so that it could improve role both internal and external roles.

\section{REFERENCES}

[1] Battaglia, M., Bianchi, L., Frey, M. \& Iraldo, F. 2010. An innovative model to promote CSR among SMEs operating in industrial clusters: Evidence from an EU project. Corporate Social Responsibility and Environmental Management 17(3):133-141.

[2] Ehnert, I. 2009. Sustainability and human resource management: reasoning and applications on corporate websites. European Journal of International Management 3(4): 419-438.

[3] Dyllick, D. \& Hockert, H. 2002. Beyond the business case for corporate sustainability business strategy and the environmental quality management 2(2):130-141.

[4] Van Marrewijk, M and M Were. 2003. Multiple Levels of Corporate Sustainability. Journal of Bussines Ethic.

[5] Bal, M.D.B. \& Fearon. D. 2013. Stakeholder engagement achieving sustainability in the construction sector.

[6] Parish, A.S. 2013. Location based automated check in to a social network recognized location using a token. U.S. Patent 8:521,180.

[7] Freeman, R. E., 1994, Strategic Management: A Stakeholder Approach, Pitman Publishing, Boston

[8] Collins, M., Knutti, R., Arblaster, J., Dufresne, J.L., Fichefet, T., Friedlingstein, P., Gao, X., Gutowski, W.J., Johns, T., Krinner, G. \& Shongwe, M. 2013. Long term climate change: projections, commitments and irreversibility. 